\title{
A SIGNIFICAÇÃO DA FILOSOFIA DA EDUCAÇÃO COMO DISCIPLINA OBRIGATÓRIA À FORMAÇÃO DO ENFERMEIRO
}

\author{
Luiz Henrique da Silva, Universidade Federal de Campina Grande- UFCG/CFP \\ luiz00henrique95@gmail.com \\ Manoel Dionizio Neto, Professor Dr. da Universidade de Campina Grande- \\ UFCG/CFP \\ dionizioneto@uol.com.br
}

\begin{abstract}
RESUMO
A enfermagem é a arte de atuar conjuntamente com o ser humano em relação às suas necessidades básicas. A formação do enfermeiro deve ser revestida pelo pensamento crítico, para isso nada melhor do que tornar visível a contribuição da Filosofia da Educação para formação, logo, por ela abranger reflexões à nível global, ao mesmo tempo em que se vê o progresso do capitalismo, percebe-se o retrocesso das pessoas. Quanto ao objetivo, buscou-se compreender a Filosofia da Educação, disciplina obrigatória no Curso de Enfermagem, com vista à formação do enfermeiro numa perspectiva crítica na atual sociedade. E como modo de abordagem da temática, utilizou-se do método explicativo e descritivo tendo em vista as abordagens feitas por diferentes autores no que se refere à formação crítica do enfermeiro. No que tange à enfermagem os autores possuem um aspecto em comum: a relação Ser - enfermeiro e Ser - paciente, assim os filósofos fazem com que emerjam reflexões acerca da necessidade do enfermeiro ser possuidor de pensamento crítico. Por fim, reconhecer o importante papel da filosofia da educação no desenvolvimento crítico do pensamento do enfermeiro, se torna cada vez mais crucial, buscando alcançar a autonomia humana e profissional, além da independência quanto ciência.
\end{abstract}

PALAVRAS-CHAVES: Enfermagem; Filosofia da Educação; Formação do Enfermeiro.

\section{THE MEANING OF THE PHILOSOPHY OF EDUCATION AS A COMPULSORY DISCIPLINE FOR THE FORMATION OF THE NURSE}

Nursing is the art of acting together with human beings in relation to their basic needs. The formation of the nurse must be coated with critical thinking, for this nothing better than to 
make visible the contribution of education's philosophy to training, so it covers reflections at the global level, while seeing the progress of capitalism, perceives the regression of people. As for the objective, it sought to understand the philosophy of education, compulsory discipline in the nursing course, with a view to the formation of the nurse in a critical perspective in the current society. And as a mode of approach to the thematic, the explanatory and descriptive method was used for the approaches made by different authors regarding the critical formation of the nurse. In the case of nursing the authors have one aspect in common: the relationship being - nurse and being - patient, so philosophers make emerge reflections on the need for the nurse to be possessed of critical thinking. Finally, recognizing the important role of education philosophy in the critical development of the nurse's thought, becomes increasingly crucial, seeking to attain human and professional autonomy, as well as independence as science.

KEYWORDS: Nursing; Philosophy of education; Formation of the nurse.

\section{INTRODUÇÃO}

A enfermagem é uma profissão aprendida, ciência e uma arte. Os enfermeiros precisam de pilares teóricos para demonstrar tais características quando promovem o processo do cuidado. Sendo que os conhecimentos práticos são distintos dos conhecimentos teóricos, aqueles são influenciados pela experiência do profissional em relação ao indivíduo, pessoa ou comunidade. Para obtenção de vasto conhecimento prático se faz necessário refletir sobre tais experiências oriundas do cuidar. Potter e Perry (2013, p. 216) avaliam que a formação do enfermeiro deve ser revestida pelo pensamento crítico, almejando profissionais que não somente façam por fazer, mas saibam como fazer, por que fazer e para quem fazer. Enfermeiro que faz somente o que lhe é recomendado não merece ser considerado como tal, isso é uma barbaridade tanto para com o indivíduo como para a profissão.

Antigamente a enfermagem atendia necessidades de combatentes nas guerras; com o passar das décadas, priorizou as necessidades da pessoa, família e coletividade, algo que se perpetua até os dias atuais. Florence Nightingale, figura ícone da enfermagem, foi a primeira pessoa a conceber uma filosofia de enfermagem, tendo como alicerce o ambiente onde as 
pessoas recebiam cuidados; ficou conhecida como a "dama da lâmpada" pelo fato de visitar os doentes à noite apenas com uma lâmpada em mãos. Somente a partir do século XX houve grandes expansões em relação às escolas de enfermagem e prática profissional (POTTER e PERRY, p. 3 e 4). Tal afirmação se deve, muito em conta, aos papéis realizados pelo enfermeiro em diferentes contextos de atenção à saúde. Sendo o raciocínio crítico de vital importância para a tomada de decisões rápidas e certeiras, quando existe o erro, serve-se como aprendizado e lacunas para novos conhecimentos.

A enfermagem possui alguns métodos que fazem a profissão ser única e singular. $\mathrm{O}$ processo de enfermagem é um instrumento presente na Sistematização da Assistência de Enfermagem (SAE), que pode abrir caminho para que a profissão alcance um termo que Kant (2010) denominou "Maioridade", que é justamente quando o indivíduo consegue usufruir de sua própria razão, não dependendo de mais ninguém. É correta a afirmativa de que isso já está se tornando realidade em outros países, mas, em terreno brasileiro, a transição da menoridade para a maioridade está caminhando lentamente. A Sistematização da Assistência de Enfermagem (SAE) é de uso exclusivo do enfermeiro, com a qual se dão as contribuições, principalmente na organização da assistência direta e indireta à pessoa, à família ou à comunidade. Nesse contexto, a utilização de meios que favoreçam o destaque do papel do enfermeiro faz com que a autonomia desse profissional não fique abafada, mas transcenda ao Ser-Enfermeiro, Ser-paciente e ao Ser- Enfermagem (HORTA, 1979).

Destarte a educação deve ser realizada com objetivos focados no futuro, mencionemos, por exemplo, nossas crianças que por sua vez devem ser educadas com base num estado melhor da humanidade, quem sabe futuramente (KANT, 2006. p, 22). No que tange a educação do enfermeiro, existem vários modelos teóricos, mas timidamente em meio ao ramo da saúde está uma disciplina de cunho obrigatório a grade curricular do Curso de Enfermagem denominada Filosofia da Educação, que contribui tanto para a formação profissional, como para o ser humano em sua existência, fazendo com que o indivíduo não seja apenas mais uma gota em meio à chuva de pessoas que fazem por fazer, não sabem o objetivo de fazer, não sabem quando fazer e para quem fazer.

Seguindo a linha de pensamento de Saviani (1973), a Filosofia em si, pode ser caracterizada entre muitos outros conceitos, pela reflexão. Mas tal reflexão para ser filosofia exige alguns requisitos como ser radical, rigorosa e de conjunto, tendo como base problemas 
advindos da realidade. De conjunto, pois o problema deve ser analisado de forma global, considerando inclusive os elementos contrários a ele, rigorosa, devido ao surgimento de críticas, sejam elas positivas ou negativas e de maneira radical, ou seja, analisar o problema em suas entranhas, suas raízes mais profundas. Destarte a Filosofia da Educação é reflexão, tendo como foco a realidade educacional. No contexto educacional, a filosofia possui como um de seus objetivos principais interrogar o homem, numa determinada realidade, partindo justamente de uma reflexão radical e global (PAVIANI, 1998).

A Filosofia se faz importante em um mundo coberto pelo capitalismo, onde o ser humano possui todas as habilidades e instrumentos necessários para erradicar a miséria de todo o globo, no entanto acontece justamente o contrário: com o passar dos, anos as tragédias só aumentam. Temos a capacidade de alcançar a liberdade, porém contentamo-nos apenas com a reprodução de nossas necessidades, toda a produção científica que temos em nossas mãos causa medo (ZUIN, 1999).

Adorno (1995) salientou que a sociedade vem caminhando por tempos tristes, onde as barbáries ocorrem cada vez mais frequentemente. Mas tendo como base uma tragédia que não se pode esquecer, e muito menos se repetir, sobre o genocídio de milhares de pessoas nos campos de concentração nazista denominados Auschwitz, pois qualquer discussão sobre a questão educacional merece ter como meta o não retrocesso, ou seja, a repetição daquele momento que marcou lamentavelmente a história da humanidade.

É justamente no capitalismo que o esclarecimento se apresenta por meio de sua contradição, ao mesmo tempo em que vemos o progresso dos produtos, percebemos o retrocesso das pessoas tanto de modo externo quanto interno, de modo que a ideologia não advém mais de uma reflexão aberta, cujos produtos são princípios e objetivos que orientam nossas ações, mas passa a ser reflexão fechada, onde não se ver qualquer aspecto conjuntamente, radicalmente e rigorosamente (ZUIN, 1999; SAVIANI, 1973).

\section{OBJETIVO}

Com base nessas reflexões, o estudo busca compreender a Filosofia da Educação disciplina, obrigatória no Curso de Enfermagem com vista à formação do enfermeiro numa perspectiva crítica em um mundo capitalista permeado pela formação tecnicista. 


\section{METODOLOGIA}

Partindo-se de alguns autores referendados no Curso de Enfermagem, busca-se compreender a contribuição deles para a formação de enfermeiro, devendo esta submeter-se à crítica proposta pela discussão filosófica que tem em vista à formação humana em geral, bem como a formação mais específica em termos profissionais, o que se fará recorrendo-se às disciplinas filosóficas da grade curricular desse Curso. Assim, tomando-se como referência o pensamento dos filósofos que têm a educação como objeto de reflexão: Antônio Álvaro Soares Zuin, Theodor W. Adorno, Immanuel Kant, Rubem Alves, Demerval Saviani e Jayme Paviani. Estabelece-se um diálogo entre autores e autoras que pensam especificamente a formação do bacharel em enfermagem, em específico Florence Nightingale, Hildegard Peplau, Virginia Henderson, Dorothea E. Orem, Wanda Horta, Tannure e Pinheiro, Potter e Perry. Para isto, faz-se uma pesquisa bibliográfica, seja em relação aos autores da área da enfermagem quanto da filosofia. Foi realizado um diálogo entre os autores selecionados da enfermagem e os filósofos.

Como critério de inclusão aqueles autores da enfermagem que fazem parte, principalmente, da formação crítica do enfermeiro. Enquanto o método de inclusão dos filósofos foram aqueles que possuíam a educação como base de suas reflexões. Foram excluídos autores que de algum modo não contemplaram o objetivo da pesquisa.

Como modo de abordagem considerando-se, neste sentido, os métodos explicativo e descritivo. Explicativo, quando o pesquisador busca explicar os porquês das coisas e suas causas, por meio do registro, da análise, da classificação, interpretação e observação dos fenômenos. No mais, procura-se identificar os fatores que influenciam positivamente ou negativamente para a ocorrência dos fenômenos (GIL, 2010), e descritivo pelo fato dos registros e descrição dos fenômenos observados serem feitos sem intervir neles. Sendo assim objetiva demonstrar as relações entre as variáveis, assumindo assim uma maneira de levantamento (PRODANOV, FREITAS, 2013).

\section{RESULTADOS E DISCUSSÃO}


Necessitando de um conjunto de conhecimentos teóricos e independência em relação às outras ciências, alguns enfermeiros buscaram conhecer a essência da enfermagem e sua identidade enquanto área do conhecimento que lida diretamente com as variáveis da saúde do ser humano. Mas os questionamentos a tais teorias não são difíceis, principalmente no âmbito acadêmico, como argumentos no estudo realizado por Almeida, Lopes, Damasceno (2005) em que estudantes questionaram sobre a aplicabilidade das teorias além do processo de formação acadêmica. Isso instigou o pensamento de que, se não houver íntima relação entre teoria e prática, a abstração intelectual será o que caracterizara aquelas teorias. A comprovação de conhecimentos no campo empírico fez-se cada vez mais iminente. Zuin (1999) apresentou afinidade com tal afirmativa, pois, para ele, era necessário a transição do contexto metafísico para o âmbito prático. Era o momento da busca pelas causas primeiras dos fenômenos considerando as leis naturais.

Florence Nightingale como destacou George (2000, p. 35) e Potter; Perry (2013, p. 49), proporcionou enorme contribuição sobre os fenômenos presentes no ambiente, como intercessor no processo saúde-doença do indivíduo. Ela não via somente a patologia como motivo para realização dos cuidados, mas acreditava que, proporcionando boas condições ambientais tanto para os pacientes, se recuperariam antecipadamente de seus enfermos, assim como as pessoas sadias não adquiririam doenças. Florence nasceu em 12 de maio de 1820, em Florença, Itália. Sempre teve uma educação ampla proporcionada por seus pais e aclamava sempre, quando podia, a religiosidade.

Como principal preceptora da enfermagem moderna, Florence foi a primeira a conceber uma filosofia da enfermagem, já supracitada, com base no ambiente. Sabemos que o ambiente é fonte de males para a saúde. Atualmente o ambiente hospitalar está relacionado, cada vez mais, com o aumento do estresse em profissionais e pacientes gerando problemas de saúde. A influência de sua teoria perpetua até hoje, pois as medidas preventivas ou até características adotadas pela vigilância sanitária e epidemiologia tiveram seus princípios lapidados por Florence Nigthtingale.

A partir do momento que o indivíduo tem domínio e capacidade de cuidar de sua própria saúde adaptando-se aos fatores externos e internos, ele não necessita dos cuidados do enfermeiro. No entanto, quando é incapaz, os cuidados necessários são prestados. Sobre esse contexto adentramos na Teoria do déficit de autocuidado da enfermeira Dorothea Orem, 
formulada no ano de 1971. O foco era justamente auxiliar o paciente a conseguir o mais rápido possível o autocuidado de todas as suas necessidades desde psicológicas as desenvolvidas socialmente (POTTER; PERRY, 2013).

No ano de 1952, a teoria das Relações Interpessoais de autoria por Hildegard Peplau, enalteceu a importância da prática de enfermagem perante à humanidade, e, em específico, no campo da enfermagem psiquiátrica. Com fundamentos nos diálogos interpessoais como fonte da recuperação, promoção e prevenção de problemas em relação ao processo saúde-doença, Peplau observava que a enfermagem realizava uma assistência deficiente em relação a humanização e dependente do profissional médico (ALMEIDA; LOPES; DAMASCENO, 2005).

Para Virginia Henderson, segundo George (2000), o ser humano é possuidor de necessidades básicas, inclusive se essas necessidades forem em relação à morte, no caso de pacientes terminais. $\mathrm{O}$ ápice funcional do enfermeiro consiste em realizar aquelas necessidades do paciente sem interferência (de suas funções exclusivas) por outros membros da equipe de saúde. Em 1955, Henderson se deparou com a deficiência da humanização presente na assistência de enfermagem, nesse período os procedimentos técnicos eram os objetivos finais dos cuidados. Será que esse cenário repleto de funções técnicas com o foco somente na doença foi erradicado? Convenhamos que não. Atualmente, com o avançar do capitalismo, cada vez mais se dá importância aos procedimentos manuais e tarefas à curto prazo que não afetem, principalmente, o capital da instituição.

Potter e Perry (2013) investem na construção do raciocínio crítico, em específico, na enfermagem, por meio de estudos baseados em evidências que proporcionam a instigação da prática profissional, destacou, em seu capítulo "Pensamento Crítico na Prática de Enfermagem", que o desenvolvimento do pensamento crítico está em ascensão na enfermagem. Portanto, exige-se um profissional que seja capaz de decidir o melhor para a pessoa que recebe seus cuidados como para a equipe de saúde. Novamente vemos aqui a necessidade da utilização do conhecimento empírico por meio da medicina baseada em evidências. Em meio aos fenômenos naturais temos que agir de acordo com a ética profissional.

Diante novas incógnitas de natureza ética que surgem na rotina dos profissionais de saúde, os profissionais devem saber analisar determinada situação problema, considerando 
princípios e valores e por fim proporcionar as respostas adequadas (OGUISSO, ZOBOLI, 2006). Entre vários princípios que regem as relações humanas, vale-se ressaltar a autonomia Ela vem provocando, timidamente, alterações no que Peplau denominada de relações interpessoais, ou seja, o paciente a partir do empoderamento vem percebendo que não se trata somente de um objeto, mas sujeito com uma bagagem social, cultural e psicológica.

Kant (2010), em seu artigo: “Resposta à pergunta: Que é 'Esclarecimento'?”, publicado como capítulo da obra Textos seletos, faz reflexões sobre competências para alcançar a autonomia humana, que só se faz possível pelo esclarecimento. Mas como chegar a esse esclarecimento? A resposta seria liberdade, aquela liberdade de raciocinar de maneira pública, pois em todos os lados vemos a limitação da liberdade, mas não é um erro ou crime, o cidadão expor o que sabe e o que pensa em benefícios ou riscos/falhas do mesmo à comunidade para que ela se esclareça.

Todavia, vejo que para se alcançar a autonomia profissional na enfermagem seria preciso a utilização eficaz dos instrumentos da própria enfermagem, além do conhecimento base das teorias de enfermagem. Não deixemos que a (SAE) fique somente no papel ou ideias flutuantes... não deixemos que o Processo de enfermagem seja apenas abstração intelectual. Em Sistematização da Assistência de Enfermagem (SAE), de Tannure e Pinheiro (2010) ressalvam justamente a importância da SAE como instrumento exclusivo do enfermeiro para tornar visível a singularidade e independência da profissão. Mas há benefícios, também, para os pacientes, por exemplo: a segurança tendo como base o conhecimento do enfermeiro para nortear a aplicabilidade da SAE.

Entre os autores selecionados em relação à enfermagem, todos possuem um aspecto em comum: a relação Ser-enfermeiro e Ser-paciente de vital eficácia para sanar os problemas apresentados por este. Por outro lado, os filósofos fazem com que emerjam reflexões acerca da necessidade do enfermeiro ser possuidor de pensamento crítico tanto em relação ao aspecto profissional como humano.

É valido afirmar que as teorias da enfermagem se encontram em contínuo desenvolvimento, a própria enfermagem encontra-se num momento de transição paradigmática. Para suprir as necessidades nessa passagem de transição, as teorias servem justamente para acrescentar o intelecto e posteriormente uso prático. Mas para atuar na prática profissional não basta conhecer apenas conceitos e ideias da enfermagem, é preciso 
reconhecer o outro lado da moeda, o lado onde existem também conhecimentos científicos que norteiam a atuação do enfermeiro. Por isso, a seguir, determinarei a importância de acrescentar nos conhecimentos de enfermagem, buscando contribuir de modo geral e em específico para o pensamento crítico desse profissional as reflexões no âmbito da Filosofia, ressaltando-se a interdisciplinaridade necessária à profissão.

O que leva o enfermeiro a filosofar? É realmente necessário, um enfermeiro filosofar? A partir do momento que a existência espontânea do homem tem seu trajeto interrompido, ele é obrigado a filosofar (SAVIANI, 1973. p, 10). A meu ver, a enfermagem é um berço esplêndido de filosofia. Por exemplo, a própria assistência da enfermagem é filosofia, pois o problema que remete o homem, enquanto enfermeiro, a refletir se encontra na questão: como sanar o problema apresentado pela pessoa/paciente de modo que suas necessidades básicas sejam supridas? Sendo assim o enfermeiro se vê obrigado a filosofar em prol desse fenômeno para em seguida agir.

O problema em questão nos faz refletir o seguinte: o enfermeiro tem que pensar de maneira crítica para tomar uma decisão frente àquele problema. A atitude que é tomada é caracterizada como filosofia. O tema é mais abrangente do que parece, de modo que, os cuidados realizados pelo enfermeiro, em determinada circunstância a ele apresentada, é "Filosofia”! Destarte a estimulação do pensamento crítico desde o início da formação se faz mutuamente notável.

Como já supracitado no decorrer da pesquisa, a Filosofia da Educação lida com problemas relacionados à realidade educacional. Porém quero deixar claro que não se limita apenas nessa afirmativa, nem a alguma teoria educacional. Uma de suas metas é justamente caminhar conjuntamente com a educação de maneira crítica avaliando as disciplinas que a compõe e por fim validar seus resultados. Lembrando que Rubem Alves (1984), já argumentava que não dispomos de métodos para avaliação da educação. Em contrapartida, também não dispomos de métodos para armazenar o produto dos cuidados realizados pelo enfermeiro - A saúde. Antes de chegar ao produto final (a saúde do indivíduo) é preciso filosofar, desde a sala de aula por meio de reflexões, entre estas reflexões do contexto educacional, o enfermeiro é por si só um educador por natureza, desse modo a disciplina é de vital ênfase no âmbito da enfermagem. A Filosofia da Educação pode facilitar o desenvolvimento do pensamento crítico para a tomada de decisões clínicas conjuntamente 
com as disciplinas específicas da enfermagem. Além do aspecto educacional que adentra mais a fundo na saúde, em específico na assistência de enfermagem. Pois a educação da pessoa, família e coletividade se faz cada vez mais vinculada à saúde na sociedade atual.

Para o enfermeiro, assim como o educador, é preciso “amor”! Não tem como o profissional exercer sua função satisfatoriamente se não houver identificação para com a mesma. Ele precisa buscar além das conquistas materiais sua realização no trabalho que executa. $\mathrm{O}$ enfermeiro tem que sentir com prazer como que faz por ter amor ao próximo, por amar aquele ou aquela que sofre e que precisa dos seus cuidados, assim como deve fazer com o educador em relação à educação e ao educando.

Na sociedade atual, sob influência do sistema capitalista - só tem importância o que se produz de imediato, ou seja, em curto prazo. São plantados eucaliptos com objetivo de substituir as árvores seculares, cujo desenvolvimento ninguém percebeu (ALVES, 1984). Sem sombra de dúvidas o caminhar tecnológico, cientifico, educacional e político são influenciados pelas necessidades do sistema que prioriza mais o lucro do que preparação digna de seus trabalhadores. O que vemos são árvores de fácil reposição pelo sistema, afinal todas são iguais. Como seres dotados de reflexão, as pessoas estão perdendo sua personalidade, pois é de mais valia sua função desempenhada na sociedade, os traços pessoais passam a ser esquecidos.

Como enfermeiro sempre haverá situações onde serão necessárias habilidades que envolvam o pensamento crítico, além de outras atribuições. Para isso a Filosofia da Educação pode contribuir para o desenvolvimento dessas atribuições. Potter e Perry (2013) explicitaram um modelo de pensamento crítico para a tomada de decisões; tal modelo é constituído por cinco componentes: 1. Base de conhecimentos Específicos; 2. Experiência; 3. Competência do Processo de Enfermagem; 4. Atitudes para o pensamento crítico e 5. Padrões de pensamento crítico, baseado neste, vejamos a aplicabilidade da Filosofia, em específico da Filosofia da Educação:

O pensamento crítico na enfermagem é bastante complexo, requer conhecimento interdisciplinar, pois pensa a pessoa de maneira holística. Sua capacidade de pensar pode ser revestida por radicalidade e de maneira global. Por exemplo: determinado paciente chega à Unidade de Saúde queixando-se de febre, dores nos ossos e articulações, dores na parte posterior dos olhos e tonturas. O enfermeiro terá que investigar a fundo o que está causando 
esses sintomas, analisá-lo por meio da metodologia científica de enfermagem e, de maneira global, verificar as condições do domicílio/ambiente e familiares dessa pessoa.

Ao fazer tais ações, o enfermeiro propicia um fator muito importante para as pessoas: a promoção em saúde. No entanto, para eficácia da educação em saúde, tendo como base reflexões sobre o meio onde o indivíduo vive, é preciso considerar suas condições socioeconômicas e questões políticas. Pois sabemos que o direito à saúde é universal e se fundamenta por meio de políticas sociais e econômicas, objetivando a diminuição de patologias.

A assistência à saúde deixou de contemplar apenas a dimensão do cuidado para adentrar em outros campos entre eles: pesquisa, administração e participação política. A participação na dimensão política não significa exclusivamente filiar-se às organizações que possuem entre seus objetivos à defesa dos direitos civis ou a um partido político. Por exemplo: atitudes morais por meio de reflexões é uma forma de participação política, mesmo o enfermeiro não tendo consciência dessa ação (SANNA, 2007).

Desse modo, o enfermeiro necessita do devido reconhecimento em relação às práticas voltadas para as políticas de saúde no país. Com o passar dos anos, os enfermeiros estão sendo cada vez mais decisivos nas decisões sociopolíticas de modo geral, de acordo com a localidade onde o enfermeiro atua, pois somente ele conhece os fenômenos que ocorrem em sua realidade. $\mathrm{O}$ enfermeiro possui tanto habilidades para a assistência direta como para a assistência indireta, ou seja, para o gerenciamento do cuidado. Justamente com o auxílio da Filosofia da Educação, ele está apto a refletir sobre as questões educacionais e humanas de modo geral, para tomar decisões para o benefício da população.

Considerando os motivos contrários aos sintomas, pois o problema só será sanado se houver uma relação conjunta entre Ser-Enfermeiro e Ser-Paciente. Se você for experiente, conseguirá solucionar de maneira mais rápida o caso; se não, dependerá de mais tempo para tal atividade. Por meio do processo de enfermagem você faz reflexões acerca do problema apresentado pelo paciente, até por fim agir e avaliar suas intervenções. Não menos importante, atuando perante os princípios éticos legais da profissão, pois pensar criticamente, também, é agir consciente de acordo com o ponto de vista do paciente.

Desde a chegada do paciente à Unidade de Saúde, o enfermeiro foi obrigado a refletir sobre: descobrir o que ele tem, que atitude tomar, avaliar os resultados esperados. Por fim, 
caberiam as orientações em educação em saúde. Como a educação não pode ser medida, vale saber se realmente aquela pessoa entendeu as orientações e por meio de visitas domiciliares e averiguar.

O pensamento crítico pode ser adquirido ao logo da formação do profissional conjuntamente com a prática (POTTER e PERRY, 2013, p. 216). Ou seja, é importante que inicie o pensamento crítico antes de sua prática, mas para isso é preciso conhecimentos teóricos que estimulem a reflexão sobre os fenômenos do cuidado.

\section{CONSIDERAÇÕES FINAIS}

Portanto, para que a enfermagem alcance seus objetivos é preciso que os discursos das instituições passem por reformulações, pois estas muitas vezes possuem uma visão mecânica e sociocultural que fazem do enfermeiro apenas uma ferramenta qualquer pela sociedade.

O pensamento crítico específico na enfermagem está centrado no processo de enfermagem, por meio de ações organizadas, buscando o bem-estar e saúde do ser humano. Cabe ao enfermeiro conhecer seus instrumentos de uso, tanto material, como principalmente intelectual, para que a enfermagem se torne sinônimo, ainda mais, de autonomia e competência profissional, onde o estabelecimento de uma relação de diálogo seja constante e eficaz entre a Filosofia e os conhecimentos baseados em evidências, sendo assim um dos principais pilares para o desenvolvimento do pensamento crítico do enfermeiro, no mais, destaca-se a importância de ser um profissional crítico e protagonista do que apenas instrumentos de manipulação do capitalismo permeado pelo tecnicismo.

\section{REFERÊNCIAS}

ADORNO, T. W. Educação e Emancipação. Rio de Janeiro: Paz e Terra, 1995.

ALMEIDA, V. C. F. de; LOPES, M. V. O. de; DAMASCENO M. M. C. Teorias das Relações Interpessoais de Peplau: Análise Fundamentada em Barnaum. Revista da Escola de Enfermagem da USP, v. 39, n. 2, 2005. Disponível em: < http://www.scielo.br/pdf/reeusp/v39n2/11.pdf/>. Acesso em: 17 ago. 2017. 
ALVES, Rubem. O preparo do Educador. In: BRANDÃO, Carlos Rodrigues (Org). O educador: vida e morte. 5. ed. Rio de Janeiro: Graal, 1984. p. 13-28. (Biblioteca de Educação; 1). Autores Associados, 1999.

GEORGE, J. B. Teorias de Enfermagem: Os Fundamentos à Prática Profissional. $4^{\circ}$. ed. Porto Alegre: ARTMED, 2000.

GIL, A. C. Métodos e técnicas de pesquisa social. 6. ed. São Paulo: Atlas, 2008.

HORTA, W. A. de. Processo de enfermagem. São Paulo: EPU, 1979.

KANT, I. Sobre a pedagogia. 5 . ed. Piracicaba: UNIMEP, 2006.

KANT, I. Textos seletos. $6^{\circ}$. ed. Petrópolis, Rio de Janeiro: Vozes, 2010.

Oguisso T, Zoboli E.L.C.P. Ética e Bioética: Desafios para a Enfermagem e a Saúde. Barueri (SP): Manole, 2006.

PAVIANI, Jayme. Problemas de Filosofia da Educação: O cultural, o Político, o Ético na Escola, o Pedagógico, o Epistemológico no Ensino. 4. ed. Petrópolis: Vozes, 1988. p. 09-18.

POTTER, P. A; PERRY, A. G. Fundamentos de Enfermagem. $8^{\circ}$. ed. Rio de Janeiro: Guanabara, 2013.

PRODRANOV, C. C.; FREITAS, E. C. de. Metodologia do Trabalho Científico: Métodos e Técnicas de Pesquisa e do Trabalho Acadêmico. $2^{\circ}$. ed. Novo Hamburgo: Feevale, 2013. Disponível em: $<$ http:file:///G:/Downloads/Ebook\%20Metodologia\%20do\%20Trabalho\%20Cientifico.pdf>. Acesso em: 23 ago. 2017. SANNA, Maria Cristina. Os Processos de Trabalho em Enfermagem. Rev. Bras. Enferm., Brasília , v. 60, n. 2, p. 221-224, 2007. Disponível em: <http://www.scielo.br/scielo.php?script=sci_arttext\&pid=S003471672007000200018\&lng=en\&nrm=iso>. Acesso em: 22 Aug. 2017.

SAVIANI, Dermeval. A filosofia na formação do educador. In: Educação: Do Senso Comum à Consciência Filosófica. 13. ed. (Revista). Campinas-SP: Autores Associados, 2000. Coleção Educação Contemporânea).

TANNURE, M. C; PINHEIRO, A. M. SAE: Sistematização da Assistência de Enfermagem: Guia Prático. $2^{\circ}$. ed. Rio de Janeiro: Guanabara Koogan, 2010.

ZUIN, A. Á. S. Indústria Cultural e Educação: o novo canto da sereia. Campinas, SP: 